\title{
Host-Plasmid Interactions in Saccharomyces cerevisiae: Effect of Host Ploidy on Plasmid Stability and Copy Number
}

\author{
By ALISON SPALDING AND MICHAEL F. TUITE* \\ Biological Laboratory, University of Kent, Canterbury, Kent CT2 7NJ, UK
}

(Received 11 July 1988; revised 15 November 1988; accepted 7 December 1988)

\begin{abstract}
The segregational stability of two chimaeric plasmids has been examined in an isogenic series of haploid, diploid and tetraploid strains of Saccharomyces cerevisiae, constructed by transformation-associated spheroplast fusion. For the highly unstable, ARS-based plasmid YRp7M, a significant increase in its segregational stability was observed with increasing ploidy, while the relatively stable, $2 \mu \mathrm{m}$-based plasmid pMA3a showed only a small increase in stability in strains of higher ploidy. The copy number of both pMA3a and the endogenous $2 \mu \mathrm{m}$ plasmid increased in proportion with the host cell ploidy, while the copy number of TRp7M was increased in the higher ploidy strains but did not correlate with ploidy. These results suggest that the copy numbers of both the $2 \mu \mathrm{m}$ plasmid and a plasmid derived from it are controlled by a nuclear gene and that, in addition, there are $2 \mu \mathrm{m}$ sequences, other than those required for the $F L P$-mediated recombination system, that play a role in maintaining copy number.
\end{abstract}

\section{INTRODUCTION}

The yeast Saccharomyces cerevisiae is rapidly becoming the micro-organism of choice for the commercial expression of recombinant proteins, and the development of high-efficiency expression vectors that can direct either intracellular or extracellular synthesis of recombinant proteins has now reached an advanced stage (see Kingsman et al., 1987; Bitter, 1987, for recent reviews). The successful large-scale exploitation of such genetically engineered strains requires the development of new host-plasmid systems that achieve high levels of expression of the recombinant protein during large-scale, and often long-term, fermentation. Of particular importance in this respect is ensuring that the structural and segregational stability of the expression plasmid is retained either in the presence or, less easily, in the absence, of selective pressure.

A range of high-copy-number chimaeric plasmids have been derived for $S$. cerevisiae (see Parent $e t$ al., 1985, for a review). They generally contain an origin of replication derived from either the endogenous $2 \mu \mathrm{m}$ plasmid (i.e. YEp plasmids) or from a region of the chromosome believed to contain an origin of replication (i.e. YRp plasmids).

The endogenous $2 \mu \mathrm{m}$ plasmid has a high copy number (50-150 per haploid cell) and is stably maintained during 'non-selective' growth via a complex series of interactions between plasmidencoded gene products (see Futcher, 1988 for a review). Yet invariably YEp plasmids that contain all or part of the $2 \mu \mathrm{m}$ plasmid are less stable than the natural plasmid, although they are generally much more stable than YRp plasmids. Attempts to improve chimaeric plasmid stability have focussed on manipulating the plasmid - for example inclusion of a functional $R E P 3$ gene from the $2 \mu \mathrm{m}$ plasmid significantly increases the stability of both YRp and YEp plasmids (Kikuchi, 1983). However, little attention has been paid to the influence of either the genetic constitution or the physiological state of the host cell on chimaeric plasmid behaviour. There is some evidence that manipulating the ploidy of the host cell may have an effect on plasmid copy number (Mead et al., 1986). 
We have undertaken a detailed study of host-plasmid interactions in $S$. cerevisiae, determining in particular whether changes in nuclear ploidy can affect the copy number and stability of chimeric YRp and YEp plasmids, and the endogenous $2 \mu \mathrm{m}$ plasmid.

\section{METHODS}

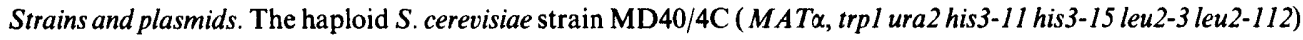
and its higher ploidy derivatives (see below) were used throughout this study.

The two chimaeric plasmids used in this study were as follows: pMA3a, a high-copy-number YEp plasmid that contains the $L E U 2-d$ (Erhart \& Hollenberg, 1983) gene and the $O R I$ and $R E P 3$ sequences of the $2 \mu \mathrm{m}$ plasmid; and YRp7M, a derivative of the plasmid YRp7, originally described by Struhl et al. (1979), that contains the entire promoter and coding sequence of the $T R P I$ gene (M. F. Tuite, S. M. Kingsman \& A. J. Kingsman, unpublished data) together with the $A R S I$ chromosomal origin of replication. The structure of these two plasmids is shown in Fig. 1.

For plasmid copy number determinations (see below) the plasmid Scp7 (obtained from Dr Brian Cox, University of Oxford) was used. This contains a $6.35 \mathrm{~kb}$ HindIII fragment of the $S$. cerevisiae ribosomal DNA repeat (containing the $18 \mathrm{~S}$ and $26 \mathrm{~S}$ ribosomal RNA genes) inserted into the HindIII site of pBR322.

Media and growth conditions. YEPD (yeast extract, $10 \mathrm{~g} \mathrm{l}^{-1}$; Bactopeptone, $10 \mathrm{~g} \mathrm{l}^{-1} ;$ glucose, $20 \mathrm{~g} \mathrm{l}^{-1}$ ) was used as the non-selective growth medium. Selective medium was minimal medium (MM: yeast nitrogen base without amino acids, $6.7 \mathrm{~g}^{-1}$; glucose, $\left.20 \mathrm{~g}^{-1}\right)$ supplemented, where appropriate, with leucine $\left(5 \mathrm{mg}^{-1}\right)$, tryptophan $\left(2 \mathrm{~m} \mathrm{l}^{-1}\right)$, histidine $\left(2 \mathrm{mg} \mathrm{l}^{-1}\right)$ and uracil $\left(10 \mathrm{mg} \mathrm{l}^{-1}\right)$. Bactoagar $\left(20 \mathrm{~g} \mathrm{l}^{-1}\right)$ was added for solid media. Growth of yeast cultures was routinely at $30^{\circ} \mathrm{C}$ with aeration; growth was monitored either spectrophotometrically (by measuring $\mathrm{OD}_{600}$ ) or by haemocytometer.

Yeast transformation. Transformation was performed essentially as described by Beggs (1978) except that spheroplasts were formed by digestion of the walls of exponential-phase cells $\left(1-2 \times 10^{7}\right.$ cells $\left.\mathrm{ml}^{-1}\right)$ with lyticase (Sigma) at a concentration of $5 \mu \mathrm{g}$ per $10^{7}$ cells for $30 \mathrm{~min}$. Spheroplast formation was monitored microscopically. Transformants were grown in selective MM-regeneration agar containing $1.2 \mathrm{M}$-sorbitol and the appropriate amino acids.

Construction and characterization of isogenic diploid and tetraploid strains. The technique used was essentially as described by Takagi et al. (1985). The haploid strain MD40/4c was transformed with the plasmid YRp7M and haploid and diploid transformants were identified initially by microscopy and whether or not they could give rise spontaneously to the recessive $\mathrm{can} l$ mutation (i.e. resistance to the toxic arginine analogue canavanine). The latter was determined by plating approximately $10^{7}$ cells onto appropriately supplemented $\mathrm{MM}$ containing $60 \mu \mathrm{g}$ canavanine sulphate $\mathrm{ml}^{-1}$ (Sigma).

To construct a tetraploid strain, first a plasmid-free diploid strain was obtained from the appropriate diploid YRp7M transformants by repeatedly subculturing on non-selective (YEPD) plates to obtain a tryptophanrequiring (and therefore plasmid-free) strain. This was then retransformed with YRp7M and the transformants were examined microscopically.

A variety of methods were used to confirm the ploidy of the strains generated by this method. A Coulter counter (Coulter Electronics) was used to estimate cell size distributions of populations of stationary-phase cells. Cell clumps were disrupted by sonication for $10 \mathrm{~s}$ on high power prior to measurement. Cell volume was calculated using latex beads $(7.8 \mu \mathrm{m}$ diameter; Coulter Electronics) as standards. DNA content was assayed by the diphenylamine method (Stewart, 1975), calf thymus DNA being used as standard since it has a similar G + C content (i.e. $40 \%$ ) to that of the $S$. cerevisiae genome. Mating ability was confirmed microscopically by examining zygote formation in crosses to a standard haploid MATa strain.

Determination of plasmid stability. (a) Long-term stability test. Plasmid-bearing strains were grown overnight at $30^{\circ} \mathrm{C}$ in selective culture to a cell density of approximately $10^{7} \mathrm{ml}^{-1}$. Portions of these cultures were then added to $50 \mathrm{ml}$ fresh, prewarmed YEPD to give a cell density of $2 \times 10^{5} \mathrm{ml}^{-1}$. This culture was then incubated for $24 \mathrm{~h}$ with aeration ( 10 generations of growth). The procedure was then repeated serially for each strain under examination until 70 generations were reached. The percentage of cells bearing plasmids at each subculture stage was determined by first plating cells onto YEPD plates, incubating at $30^{\circ} \mathrm{C}$ for $2 \mathrm{~d}$, and then replica plating at least 50 colonies onto supplemented MM lacking leucine or tryptophan as appropriate.

(b) Short-term stability test. Plasmid-bearing cells were grown overnight at $30^{\circ} \mathrm{C}$ in selective broth culture. A $1 \mathrm{ml}$ volume of this culture was then inoculated into $100 \mathrm{ml}$ of fresh, prewarmed YEPD and incubated with aeration at $30^{\circ} \mathrm{C}$. Growth was monitored until early exponential phase (point A; approximately $10^{6} \mathrm{cells} \mathrm{ml}^{-1}$ ) was reached. A sample was then taken and, following appropriate dilutions in sterile water, plated onto four YEPD and four selective plates (MM-Trp or MM-Leu as appropriate). Incubation of the culture was continued for a further three generations, at which time (point B) a further sample was removed and plated as above. Plates were incubated at $30^{\circ} \mathrm{C}$ for $2-3 \mathrm{~d}$. 

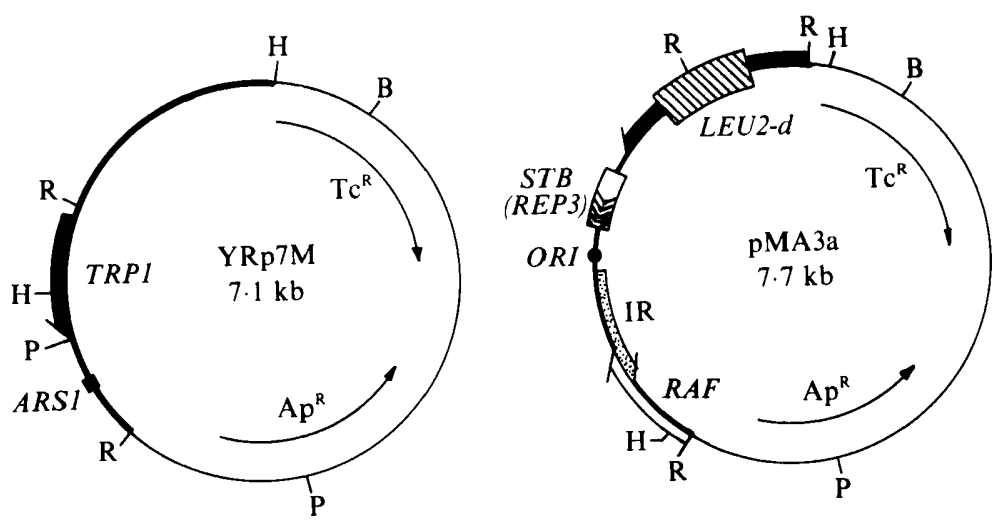

Fig. 1. Structure of the yeast chimaeric plasmids YRp7M and pMA3a. (a) YRp7M : consists of pBR322 (thin line), and $2.9 \mathrm{~kb}$ of yeast DNA (thick line) carrying the TRPl gene and $A R S l$ origin as indicated. (b) pMA3a: consists of pBR322 (thin line), and a $3.45 \mathrm{~kb}$ yeast DNA fragment containing the chromosomal $L E U 2-d$ gene, and the $S T B(R E P 3), O R I$, IR (inverted repeat) and $R A F$ sequences of the $2 \mu \mathrm{m}$ plasmid. Restriction sites: R, EcoRI; H, HindIII; B, BamHI; P, PstI.

Plasmid instability was expressed as the proportion of plasmid-bearing cells that lost the plasmid at cell division during exponential growth. This was calculated from:

$$
\frac{1-(b / a)}{x}=i
$$

where $a$ is the percentage of plasmid-bearing cells at point $\mathrm{A}, b$ is the percentage of plasmid-bearing cells at point $\mathrm{B}, \boldsymbol{x}$ is the number of generations of exponential growth between $a$ and $b$, and $i$ is the instability coefficient. Values of $i$ can theoretically range between 0 (for a totally stable plasmid) and 1 (for a totally unstable plasmid).

At least two independent estimates of $i$ were obtained for each host-plasmid combination examined.

Plasmid copy number determination. The non-isotopic technique originally described by Futcher \& Cox (1984) was used. Total DNA was extracted from cultures growing exponentially on selective medium, using essentially the method described by Holm et al. (1986). This DNA was digested with EcoRI (Boehringer Mannheim) and electrophoresed through a $1 \%(\mathrm{w} / \mathrm{v})$ agarose gel. Ethidium-bromide-stained gels were photographed and a BioRad densitometer used to scan the negatives. Relative peak areas were determined by cutting and weighing, the $3.0 \mathrm{~kb}$ rDNA fragment peak being used as the internal standard. It was assumed that the haploid genome of yeast carries 140 copies of the ribosomal DNA (rDNA) repeat (Bell et al., 1977). The relative sizes of the fragments being examined were taken into account in the calculations. At least two independent estimates of copy number were obtained for each host-plasmid combination under examination, the same transformant being used for each replicate.

\section{RESULTS}

\section{Construction and characterization of an isogenic ploidy series}

Determination of the consequences of manipulating host cell ploidy on chimaeric plasmid stability and copy number required the generation of a set of truly isogenic strains with increasing ploidies and without the genetic heterozygosity brought about by mating two haploid strains of opposite mating type. We used the technique of transformation-associated spheroplast fusion (Takagi et al., 1985) to construct a diploid ( $2 n)$ and tetraploid (4n) derivative of the strain MD40/4c. As shown in Table 1, the DNA content per cell confirmed the ploidy of the $2 n$ and $4 n$ strains constructed. Homozygosity at the $M A T$ locus was confirmed by the ability of all three strains to mate with a $M A T$ a strain, and their failure to sporulate. Both cell dry weight and cell size increased with ploidy, but not in proportion to chromosome number. An increase in doubling time of these strains grown in YEPD, with increasing ploidy, was also noted (Table 1). 
Table 1. Characteristics of haploid ( $n)$ diploid $(2 n)$ and tetraploid $(4 n)$ derivatives of the

$S$. cerevisiae strain MD40/4c constructed by transformation-associated spheroplast fusion

$\begin{array}{ccccc}\text { Strain* } & \begin{array}{c}\text { DNA content } \\ \text { per cell } \dagger \\ (\mathrm{fg})\end{array} & \begin{array}{c}\text { Modal cell } \\ \text { volume } \\ (\mathrm{fl})\end{array} & \begin{array}{c}\text { Cell dry } \\ \text { weight } \\ (\mathrm{pg})\end{array} & \begin{array}{c}\text { Culture } \\ \text { doubling time } \\ (\mathrm{min})\end{array} \\ \mathrm{n} & 20.1 \pm 1.3 & 98 & 22.9 \pm 0.9 & 82 \\ \text { 2n } & 40.7 \pm 1.4 & 146 & 33.6 \pm 1.9 & 87 \\ \text { 4n } & 78.5 \pm 7.9 & 153 & 74.0 \pm 29.5 & 103\end{array}$

*Genotype leu2-3 leu2-112 his3-11 his3-15 trpl ura2.

†Mean and standard deviation calculated from two independent determinations.

†Mean and standard deviation calculated from three independent determinations using stationary-phase cultures. Four samples were examined for each individual determination.

Table 2. Effect of host strain ploidy on the rate of loss of per cell division (i) of two chimaeric plasmids, pMA3a and YRp7M

\begin{tabular}{|c|c|c|}
\hline \multirow[b]{2}{*}{ Strain } & \multicolumn{2}{|c|}{$\begin{array}{l}\text { Rate of plasmid loss per cell } \\
\text { division }(i)^{*}\end{array}$} \\
\hline & YRp7M & pMA3a \\
\hline $\mathbf{n}$ & $0.578 \pm 0.061$ & $0.064 \pm 0.024$ \\
\hline $2 n$ & $0.278 \pm 0.065$ & $0.041 \pm 0.022$ \\
\hline $4 n$ & $0.078+0.046$ & $0.036 \pm 0.029$ \\
\hline
\end{tabular}

* Mean and standard deviation calculated from two independent determinations.

Stability of chimaeric plasmids in strains of different ploidy

Two multicopy chimaeric plasmids were chosen to examine the consequences of ploidy manipulation on stability and copy number: pMA3a, a YEp plasmid containing the $2 \mu \mathrm{m}$ plasmid $O R I$ (origin of replication) and the LEU2-d selectable gene (Erhart \& Hollenberg, 1983); and YRp7M, a derivative of the YRp plasmid YRp7 (Struhl et al., 1979) that contains a chromosomal $A R S I$ replicator and the selectable $T R P 1$ gene with an intact $T R P I$ promoter (M. F. Tuite, S. M. Kingsman \& A. J. Kingsman, unpublished data).

After transformation of each of these two plasmids into the $n, 2 n$ and $4 n$ strains, the stability of the plasmids following transfer from selective to non-selective growth conditions was examined in two ways: $(a)$ by calculating the rate of plasmid loss per cell division $(i)$ during exponential growth; and $(b)$ by monitoring the appearance of plasmid-free cells during 70 generations of growth in non-selective medium.

As shown in Table 2, although the plasmid YRp7M was significantly less stable than pMA3a in the haploid strain, the rate of segregational loss of $\mathrm{YRp} 7 \mathrm{M}$ was greatly reduced by increasing the ploidy of the strain. Using standard methods for analysis of variance, this observed increase in stability was found to be significant $(F>P=0.01)$. The slight increase in stability of pMA3a with increasing ploidy (Table 2$)$ was not statistically significant $(F<P=0.20)$.

The kinetics of loss of these two plasmids in each strain of different ploidy is shown in Fig. 2. pMA3a was very stable in all three strains of different ploidy in the absence of selection for plasmid retention, with more than $80 \%$ of cells carrying the plasmid after 70 generations in all three strains. On the other hand YRp7M was rapidly lost from all three strains with exponential kinetics, although the number of generations required to observe complete loss increased from 10 for the haploid strain, to 50 for the $4 \mathrm{n}$ strain. As previously shown for other YRp plasmids (Struhl et al., 1979), under selective growth conditions YRp7M was only found in a proportion of the cells, but that proportion increased with increasing ploidy: $n, 4.5 \%, 2 \mathrm{n}, 10.5 \%$, and $4 \mathrm{n}$, $24.9 \%$ respectively. pMA3a was maintained in $100 \%$ of all three strains grown under selection. 


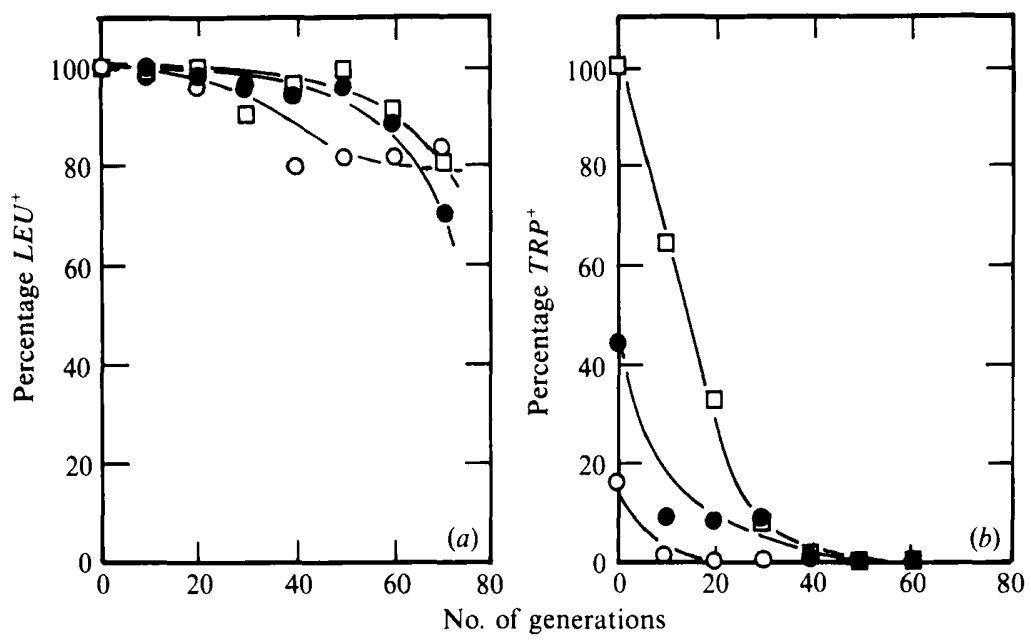

Fig. 2. The stability of yeast chimaeric plasmids pMA3a (a) and YRp7M $(b)$ in strains of different ploidy during non-selective growth. Loss of a plasmid-borne marker (LEU2 for pMA3a; TRPI for YRp7M) was monitored for 70 generations in transformed haploid $(O)$, diploid $(O)$ and tetraploid $(\square)$ derivatives of MD40/4c.

\section{Copy number of chimaeric plasmids in strains of different ploidy}

The most plausible explanation for the observed increase in the stability of YRp7M with increasing ploidy is that its copy number increases proportionately, thus decreasing the probability of segregating plasmid-free cells in the absence of a functional centromere. Therefore the copy numbers of both pMA3a and YRp7M were quantified relative to that of the ribosomal RNA (rRNA) genes (taken to be present as 140 copies in this strain; Bell et al., 1977); the results are shown in Fig. 3 and Table 3. The number of plasmid-bearing cells was taken into account when the copy numbers were determined for YRp7M, and corrected accordingly. pMA3a copy number was found to increase in proportion to ploidy, i.e. the plasmid copy number per haploid genome was not statistically different in the $n, 2 n$ and $4 n$ strains $(F<P=0 \cdot 20)$. In contrast, there was more variability in YRp7M copy number in plasmidbearing strains, a statistically significant drop in copy number per haploid genome being observed in the $4 \mathrm{n}$ strain $(F>P=0.01)$. These results suggest that the copy number of the two plasmids under study does not solely determine their stability since YRp7M had a copy number approximately five times that of pMA3a in plasmid-bearing cells in the haploid strain. In addition, the copy number of pMA3a was much more tightly controlled, at a constant level of approximately 150 per haploid genome, compared to YRp7M.

\section{Effect of host cell ploidy on $2 \mu$ m plasmid copy number}

Mead et al. (1986) have previously reported that a diploid strain heterozygous for the $M A T$ locus (i.e. $M A T \alpha / M A T$ a) contained an approximately twofold higher number of copies of the endogenous $2 \mu \mathrm{m}$ plasmid, compared with the two haploid parent strains. We therefore determined the $2 \mu \mathrm{m}$ plasmid copy number in the $n, 2 n$ and $4 n$ strains that are homozygous for mating type. The results (Table 3 ) demonstrate that host cell ploidy had no significant effect on $2 \mu \mathrm{m}$ plasmid copy number per haploid genome $(\boldsymbol{F}<\boldsymbol{P}=0 \cdot 20)$. Thus the ploidy control of copy number seen for the YEp plasmid also operates for the endogenous $2 \mu \mathrm{m}$ plasmid.

In cells transformed with pMA3a there was a significant $(F>P=0.05)$ decrease in the copy number of the $2 \mu \mathrm{m}$ plasmid (Table 3 ) although the copy number per haploid genome remained constant. 


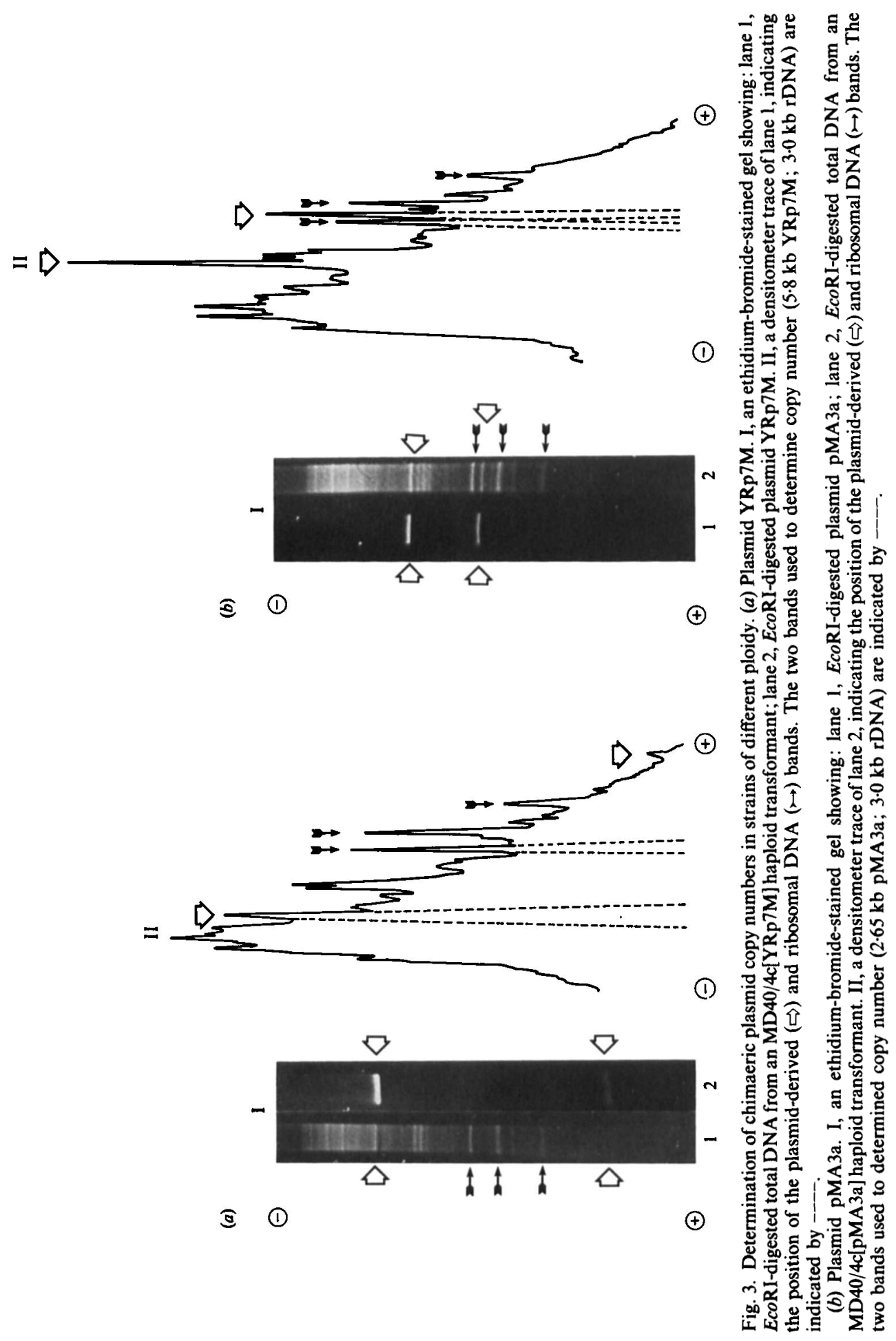


Table 3. Copy number of the chimaeric plasmids pMA3a and YRp7M, and the endogenous $2 \mu m$ plasmid, in hosts of different ploidy

\begin{tabular}{ccccc} 
Host & \multicolumn{4}{c}{ Plasmid copy number per haploid genome* } \\
ploidy & pMA3a & YRp7M & $2 \mu \mathrm{m}$ & $2 \mu \mathrm{m} \dagger$ \\
$\mathrm{n}$ & $133 \pm 59$ & $952 \pm 391$ & $147 \pm 13$ & $80 \pm 52$ \\
$2 \mathrm{n}$ & $147 \pm 64$ & $915 \pm 57$ & $140 \pm 10$ & $83 \pm 34$ \\
$4 \mathrm{n}$ & $199 \pm 24$ & $319 \pm 123$ & $108 \pm 16$ & $92 \pm 47$
\end{tabular}

*All chimaeric plasmid copy numbers given have been corrected to account for the proportion of cells without plasmid. The data presented are the means and standard deviations of at least two independent determinations. †In strains also carrying the chimaeric plasmid pMA3a.

\section{DISCUSSION}

Plasmid copy number and stability. The segregational stability of a plasmid depends on its being efficiently partitioned between mother and daughter cell during cell division. Failure to do so will give rise ultimately to plasmid-free cells. In such a situation, if segregation occurs on a purely random basis, a plasmid present at a high copy number should generate plasmid-free cells much less frequently than a plasmid with a lower copy number (Walmsley et al., 1983). For example the endogenous $2 \mu \mathrm{m}$ plasmid of $S$. cerevisiae has a copy number of about 100 in a haploid cell (Gerbaud \& Guerineau, 1980; Mead et al., 1986; data reported here) and shows no mother-daughter bias during mitotic segregation (Murray \& Szostak, 1983; Reynolds et al., 1987). This natural plasmid is lost from a cell population at a rate of approximately $10^{-4}$ per generation (Futcher \& Cox, 1983), which is significantly more frequent than would be predicted for an efficiently partitioned plasmid based on the above assumption (Futcher, 1988). The $2 \mu \mathrm{m}$ plasmid is, however, more stable than either chimaeric plasmids derived from it (i.e. YEp plasmids), or chimaeric plasmids based on chromosomal ARS sequences (i.e. YRp plasmids) even though in many cases the chimaeric plasmids are present in higher copy numbers. The stability of the YRp plasmid we have employed (YRp7M - see Fig. 1) in a haploid strain is significantly less than that of the YEp plasmid (pMA3a - see Fig. 1) in spite of having an approximately sevenfold higher copy number. The reasons for this discrepancy are twofold: $(a)$ YRp plasmids have no effective, plasmid-encoded partition system, and $(b)$ they show a strong segregation bias towards the mother cell during mitotic division (Murray \& Szostak, 1983; Kikuchi, 1983). pMA3a is also a very stable plasmid even in the absence of selection (Fig 2): this is probably due to the presence of the cis-acting $S T B(R E P 3)$ sequence of the $2 \mu \mathrm{m}$ plasmid on the chimaeric plasmid, in addition to the $2 \mu \mathrm{m}$ plasmid origin of replication (ORI). The $S T B(R E P 3)$ sequence, in conjunction with the trans-acting $R E P 1$ and $R E P 2$ gene products encoded by the endogenous $2 \mu \mathrm{m}$ plasmid, ensures a high degree of segregational stability (Kikuchi, 1983; Murray et al., 1987; Reynolds et al., 1987). pMA3a also carries the partially defective LEU2-d allele that generally ensures a high copy number for the plasmid carrying it because of the requirement for many copies of the gene to provide enough of the LEU2 gene product ( $\beta$ isopropylmalate dehydrogenase) to fully complement the host leu2 mutation (Erhart \& Hollenberg, 1983).

The above discussion implies that having a plasmid with a high copy number does not necessarily guarantee that it will be stably segregated unless that plasmid has at least a partially effective partitioning system such as that found with the $2 \mu \mathrm{m}$ plasmid. Our studies, reported here, on the stability of two chimaeric plasmids in strains of different ploidy do to some extent confirm this. For example, in a diploid cell, plasmid YRp7M, in spite of having a copy number of approximately 1800 per plasmid-bearing cell, has a stability only one-fifth that of pMA3a in a haploid strain where its copy number is around 150 per cell. Our results do however show that there is a marked increase in the stability of YRp7M with increasing ploidy and the copy number data imply that some other factor, apart from copy number, is involved. 
Control of copy number. The mechanism for setting the maximum copy number of a chimaeric plasmid in yeast is largely unknown. What little is known comes from studies on the $2 \mu \mathrm{m}$ plasmid: the copy number of this endogenous plasmid can be amplified, in response to deficiencies in the partition system, by a plasmid-mediated recombination system employing the FLP gene product and the two inverted repeat (IR) sequences present on the molecule (Futcher, 1986; Volkert \& Broach, 1986; Murray et al., 1987; Reynolds et al., 1987). What determines the maximum copy number of the $2 \mu \mathrm{m}$ plasmid is unknown. One possibility is that the $F L P$ activity must in some way be regulated with respect to copy number since controlled overexpression of the FLP gene product leads to both an increase in $2 \mu \mathrm{m}$ plasmid copy number, and an increase in cell size and lethality (Murray et al., 1987; Reynolds et al., 1987). The detrimental consequences of raising the $2 \mu \mathrm{m}$ plasmid copy number in a haploid strain appear to be caused by an imbalance in the regulatory network leading to an elevation in the levels of synthesis of the trans-acting REPI and REP2 gene products.

Our results, together with those of Mead et al. (1986) showing that the copy number of the $2 \mu \mathrm{m}$ plasmid increases in proportion with ploidy, but with little detrimental effect, imply that a nuclear-encoded function may play an important role in regulating the expression of the FLP gene and, subsequently, the $2 \mu \mathrm{m}$ copy number. Thus, having two copies of this gene allows for a stoichiometric increase in the plasmid copy number. One candidate for this nuclear regulator of $2 \mu \mathrm{m}$ plasmid copy number is the NIBl gene: mutations in this gene lead to slow growth and cell lethality only in $2 \mu \mathrm{m}$-plasmid-containing strains, a phenotype believed to be due to defective control of $2 \mu \mathrm{m}$ plasmid copy number (Holm, 1982a,b). It would be of interest to determine the consequences of controlled overexpression of the NIBI gene product on $2 \mu \mathrm{m}$ plasmid copy number.

The above discussion implies that to achieve an elevated copy number in strains of higher ploidy also requires a functional $F L P$-mediated recombination system. The results of Mead et al. (1986), who found that the copy number of the chimaeric YEp plasmid pJDB219 (Beggs, 1978) doubled in diploid cells, are consistent with this notion. However, pMA3a does not encode a functional FLP gene product nor the REP1 and REP2 products, and carries only one of the inverted repeat sequences that contains the target for $F L P$-mediated recombination (Fig. 1). Yet, its copy number also increases in proportion to ploidy (Table 3). While the REPI and REP2 functions, and presumably the $F L P$ function, can be provided in trans by the endogenous $2 \mu \mathrm{m}$ plasmid (which is increasing in proportion to ploidy), pMA3a does not contain a second copy of the inverted repeat sequence thought necessary for amplification by the double rolling circle model of Futcher $(1986,1988)$. One possibility is that another sequence on pMA3a can function as a $F L P$ recombination target, although we have found that pMA3a is structurally stable over 100 generations of selective growth in the haploid $2 \mu \mathrm{m}$-plasmid-containing strain used here (Akhamaloka \& M. F. Tuite, unpublished data). These results therefore suggest that some other $2 \mu \mathrm{m}$ plasmid sequence may be important for copy number control, the most likely candidate being the origin of replication $(O R I)$ that is immediately adjacent to the single inverted repeat. Perhaps there exists an 'origin counting' control system analogous to those proposed for Escherichia coli (Summers \& Sherratt, 1984) whereby a cell can only maintain a fixed number of active origins of replication. This is supported by the finding that the copy number of the endogenous $2 \mu \mathrm{m}$ plasmid is significantly reduced in YEp-plasmid-containing cells (Gerbaud \& Guerineau, 1980; and Table 3) although the total number of $O R I$ sequences is increased in these transformants compared to untransformed cells. Again a nuclear gene product may be implicated as the 'origin counter', one candidate being the MAPI gene: mutations in this gene affect not only the copy number of the $2 \mu \mathrm{m}$ plasmid and a YEp plasmid, but also the maintenance of ARS-based plasmids (Maine et al., 1984; Kikuchi \& Toh-E, 1986).

We have therefore demonstrated that the stability and copy number of chimaeric plasmids in $S$. cerevisiae can be increased by the simple manipulation of increasing host cell ploidy. It remains to be seen whether strains of higher ploidy are more productive hosts for the expression of recombinant proteins.

This work was supported in part by a project grant from the SERC Biotechnology Directorate and an SERC studentship to A.S. 


\section{REFERENCES}

BegGs, J. D. (1978). Transformation of yeast by a replicating hybrid plasmid. Nature, London 275, 104 109.

Bell, G. I., De Gennaro, L. J., Gelfand, D. H., Bishop, R. J., Valenzuela, P. \& Rutter, W. J. (1977). Ribosomal RNA genes of Saccharomyces cerevisiae. 1. Physical map of the repeating unit and location of the regions coding for $5 \mathrm{~S}, 5.8 \mathrm{~S}, 18 \mathrm{~S}$ and $25 \mathrm{~S}$ ribosomal RNAs. Journal of Biological Chemistry 252, 8118-8125.

BITTER, G. A. (1987). Heterologous gene expression in yeast. Methods in Enzymology 152, 673-684.

ERHART, E. \& HollenberG, C. P. (1983). The presence of a defective $L E U 2$ gene on $2 \mu$ DNA recombinant plasmids of $S$. cerevisiae is responsible for curing and high copy number. Journal of Bacteriology 156, 625635.

FuTCHER, A. B. (1986). Copy number and amplification of the $2 \mu \mathrm{m}$ plasmid of Saccharomyces cerevisiae. Journal of Theoretical Biology 119, 197-204.

FUTCHER, A. B. (1988). The $2 \mu \mathrm{m}$ circle plasmid of Saccharomyces cerevisiae. Yeast 4, 27-40.

FutChER, A. B. \& Cox, B. S. (1983). Maintenance of the $2 \mu \mathrm{m}$ circle plasmid in populations of Saccharomyces cerevisiae. Journal of Bacteriology 154, 612622.

FutCher, A. B. \& Cox, B. S. (1984). Copy number and the stability of $2 \mu \mathrm{m}$ circle-based artificial plasmids of Saccharomyces cerevisiae. Journal of Bacteriology 157, 283-290.

Gerbaud, C. \& Guerineau, M. (1980). $2 \mu \mathrm{m}$ plasmid copy number in different yeast strains and repartition of endogenous and $2 \mu \mathrm{m}$ chimaeric plasmids in transformed strains. Current Genetics 1, 219-228.

Holm, C. $(1982 a)$. Clonal lethality caused by the yeast plasmid $2 \mu$ DNA. Cell 29, 585-594.

HoLm, C. $(1982 b)$. Sensitivity to the yeast plasmid $2 \mu$ DNA is conferred by the nuclear allele nibl. Molecular and Cellular Biology 2, 985-992.

Holm, C., Meeks-Wagner, D. W., Fangman, W. L. \& BotsteIn, D. (1986). A rapid efficient method for isolating DNA from yeast. Gene 42, 169-173.

KIKUCHI, Y. (1983). Yeast plasmid requires a cis-acting locus and two plasmid proteins for its stable maintenance. Cell 35, 487-493.

KIKUCHI, Y. \& ToH-E, A. (1986). A nuclear gene of Saccharomyces cerevisiae needed for stable maintenance of plasmids. Molecular and Cellular Biology 6, 4053-4059.

Kingsman, S. M., Kingsman, A. J. \& Mellor, J. (1987). The production of mammalian proteins in Saccharomyces cerevisiae. Trends in Biotechnology 5 , 53-57.
Maine, G. T., Sinha, P. \& Tye, B.-K. (1984). Mutants of Saccharomyces cerevisiae defective in the maintainance of mini-chromosomes. Genetics 106, 365385.

Mead, D. J., Gardner, D. C. J. \& Oliver, S. G. (1986). Enhanced stability of a $2 \mu$-based recombinant plasmid in diploid yeast. Biotechnology Letters 8 , 391-396.

Murray, A. W. \& Szostak, J. W. (1983). Pedigree analysis of plasmid segregation in yeast. Cell 34, 961-970.

Murray, J. A. H., Scarpa, M., Rossi, N. \& Cesareni, G. (1987). Antagonistic controls regulate copy number of the yeast $2 \mu \mathrm{m}$ plasmid. EMBO Journal 6, 4205-4212.

Parent, S. A., Fenimore, C. M. \& Bostian, K. A. (1985). Vector systems for the expression, analysis and cloning of DNA sequences in Saccharomyces cerevisiae. Yeast 1, 83-138.

Reynolds, A. E., Murray, A. W. \& Szostak, J. W. (1987). Roles of the $2 \mu \mathrm{m}$ gene products in stable maintenance of the $2 \mu \mathrm{m}$ plasmid of Saccharomyces cerevisiae. Molecular and Cellular Biology 7, 35663573.

SteWART, P. R. (1975). Analytical methods for yeasts. Methods in Cell Biology 13, 122-123.

Struhl, K., StinchComb, D. T., Scherer, S. \& Davis, R. W. (1979). High-frequency transformation of yeast: autonomous replication of hybrid DNA molecules. Proceedings of the National Academy of Sciences of the United States of America 76, 10351039.

Summers, D. K. \& SherratT, D. J. (1984). Multimerisation of high copy number plasmids causes instability: ColEl encodes a determinant essential for plasmid monomerization and stability. Cell 36, 1097-1103.

Takagi, A., Harashima, S. \& Oshima, Y. (1985). Hybridisation and polyploidisation of Saccharomyces cerevisiae strains by transformation-associated cell fusion. Applied and Environmental Microbiology 49, 244-246.

VOLKerT, F. C. \& BROACH, J. R. (1986). Site-specific recombination promotes plasmid amplification in yeast. Cell 46, 451-550.

WALMSLey, R. M., Gardner, D. C. J. \& Oliver, S. G. (1983). Stability of a cloned gene in yeast grown in chemostat culture. Molecular and General Genetics 192, 361-365. 